\title{
Nutrient Uptake and Utilization and Antioxidants of Fruits in Red Raspberry (Rubus idaeus L.) Cultivar 'Autumn Bliss' in response to Fertilization under Extended Photoperiod
}

\author{
Baiyi $\mathrm{AN}^{1}$, Hongxu $\mathrm{WEI}^{2 *}$, Linlin $\mathrm{LI}^{3}$, Peng GUO ${ }^{3 *}$ \\ ${ }^{1}$ Jilin Agricultural University, College of Horticulture, 2888 Xincheng Street, Changchun 130118, Jilin, \\ China; swabyswaby@163.com \\ ${ }^{2}$ Chinese Academy of Sciences, Northeast Institute of Geography and Agroecology, 4888 Shengbei Street, Gaoxin North District, \\ Changchun 130102, Jilin, China; weihongxu@iga.ac.cn (*corresponding author) \\ ${ }^{3}$ Dalian Nationalities University, Environment and Resources College, 18 Liaohe West Road, District of Economy and Technology \\ Developments, Dalian 116600,Liaoning, China; 107112682@qq.com;gp@dlnu.edu.cn (*correspondingauthor)
}

\begin{abstract}
Annual-fruiting cultivars of red raspberry (Rubus idaeus L.) complete its entire cycle of vegetative growth, flowering, and fruiting in one growing season, which has not been well studied in response to treatments of photoperiod and fertilization. In this study, micro-propagated plantlets of 'Autumn Bliss' were planted in a greenhouse at Dalian, Northeast China. Some were treated with fertilizers at the rate of $12 \mathrm{~g}$ per plant $\left(\mathrm{N}-\mathrm{P}_{2} \mathrm{O}_{5}-\mathrm{K}_{2} \mathrm{O}, 14-14-14\right)$ under extended photoperiod of $17 \mathrm{~h}$ with PPFD of $240 \mu \mathrm{mol} \mathrm{m}^{-2} \mathrm{~s}^{-1}$ at dark-time (Pho.+Fert.), while others were treated with longer photoperiod (Pho.) or with the control. Compared to the control, both growth and biomass in shoot part of 'Autumn Bliss' were promoted by the Pho.+Fert. treatment, but foliar nutrients declined as the symptom of nutrient dilution. The Pho. treatment had no effect on either growth or nutrient uptake in leaves, resulting in the symptom of nutrient depletion compared to the Control. Soil P availability positively correlated with foliar $\mathrm{P}$ concentration but negatively correlated with root length. Only the Pho.+Fert. treatment resulted in the advance of fruiting by two months at July when fruits were measured to have acceptable fruit weight of about $3 \mathrm{~g}$ and contents of anthocyanin at $\sim 26.4 \mathrm{mg}$ cyaniding-3-glucoside equiv. $100 \mathrm{~g}^{-1} \mathrm{Fw}$ and total phenolic content at $\sim 17.5 \mathrm{mg} \mathrm{GAE} 100 \mathrm{~g}^{-1} \mathrm{Fw}$.
\end{abstract}

Keywords: autumn-bearing stock; caneberry; fruit phenology; prolonged illumination; vector analysis

\section{Introduction}

The red raspberry (Rubus idaeus L.) is a caneberry species with short-lived woody shoots borne on a long-lived perennial root system (Sønsteby and Heide, 2008, 2009). Red raspberry is an excellent source of natural antioxidants (Dragišić Maksimović et al., 2013); hence it is widely grown across all temperate and cold regions of the world (Heide and Sønsteby, 2011). There have been more than 40 countries signed as a group member of red raspberry development with the overall area of about $2 \times 105$ ha worldwide. Up to 2014, red raspberry cultivation has occupied $\sim 6560$ ha and $\sim 5900$ ha in the United States (Strik and Bryla, 2015; USDA, 2015) and China, respectively. Continuously increasing interest in the cultivation of red raspberry worldwide inspires better understanding of the environmental manipulation in annual-fruiting cultivars.
Red raspberry has been commercially developed as two cultivars. Biennial-fruiting cultivars have a 2-year life-cycle through vegetative growth, overwinter, flowering, and fruiting in summer. On the other hand, annual-fruiting cultivars complete their whole life-cycle in a single growing season and fruit in autumn (Heide and Sønsteby, 2011). The environmental control of growth and development has been well understood in biennial-fruiting red raspberry with manipulations on temperature and photoperiod (Heide and Sønsteby, 2011; Sønsteby et al., 2013), but much less is known about annual-fruiting cultivars. Literature reported that flowering and fruit maturation of annual-fruiting cultivars were advanced at general temperatures of $15 \sim 25^{\circ} \mathrm{C}$ (Carew et al., 2003; Sønsteby and Heide, 2012) and sometimes their floral primordial can be initiated at temperature as high as $30^{\circ} \mathrm{C}$ (Sønsteby and Heide, 2009). Photoperiod treatment from $8 \mathrm{~h}$ to $17 \mathrm{~h}$ seemed to have no consistent effect on their growth and flowering (Carew et al., 2003; Sønsteby and Heide, 2009). For the annual- 
cultivar 'Polka', the longer photoperiod tended to stimulate vegetative growth and advance flowering (Carew et al., 2003; Sønsteby and Heide, 2009). Other manipulations have also been reported to affect annual-fruiting cultivars' growth and production, such as mycorrhiza inoculation (Jones and McGavin, 1998; Campos-Mota et al., 2004), $\mathrm{NaCl}$ stress (Neocleous and Vasilakakis, 2007), chilling (Carew et al., 2001; Neocleous et al., 2005), and pruning (Oliveira et al., 2004). However, most significance of these manipulations appeared to be lower than photoperiod and temperature on cane growth and flowering initiation of annual-fruiting raspberries.

Commercial caneberry growers are encouraged to develop fertilization programs based on initial nitrogen $(\mathrm{N})$ recommendations with adjustments made to $\mathrm{N}$ and other nutrients as needed. Strik and Bryla (2015) summarized that $\mathrm{N}$ application may increase primocane number and advance growth and flowering, thus increasing yield of annual-fruiting raspberry cultivars, whose response of biomass, however, was not different to nitrate or ammonium forms of $\mathrm{N}$. Other elements rather than $\mathrm{N}$ have also been added to red raspberries both as organic amendment and as mineral fertilizers (Horuz et al., 2013). Boron (B) was found to be the main micronutrient that increased yield of raspberries, and tissue phosphorus (P) concentration in raspberry was found to significantly respond to $\mathrm{N}$ and $\mathrm{B}$ fertilizations (Kowalenko, 2006). In addition to $\mathrm{B}, \mathrm{P}$ and potassium $(\mathrm{K})$ were both found to tend to undergo deficiency risks in several raspberry cultivars (Horuz et al., 2013). Dean et al. (2000) found that $\mathrm{N}$ fertilization lost most of its effect on growth and $\mathrm{N}$ uptake in raspberry unless soils were amended by manure. Compared to results about environmental control, our knowledge about fertilization of red raspberry is much less and most results in fertilizer experiments were obtained for biennial-fruiting cultivars with quite few studies supplying information about nutritional manipulation on red raspberry cultivars.

Northeast China $\left(38 \sim 50^{\circ} \mathrm{N}\right)$ is one of the largest red raspberry plant area in China, where about 3000 ha of lands are used for red raspberry planting and total fruit production is estimated to over $2 \times 10^{4}$ ton. Annual-fruiting cultivar is the main red raspberry in Northeast China and accounts for about $70 \%$ of all planting reserve. Pruning technique is widely used as within the practical protocol of red raspberry culture to promote the fruit production in Northeast China. Generally, 10 to 15 canes per square meter are left by pruning primocanes emerged from crown buds (Oliveira et al., 2004) so as to gain about $0.6 \mathrm{~kg}$ plant ${ }^{-1}$ of yield from September to mid-October (Xu et al., 2015). However, this region was found to suffer early autumn frost events in recent years (Yin et al., 2016) which have caused significant impact on yield of red raspberry. Therefore, alternative harvest time is demanded to avoid the shock of chilling by some environmental controls.

According to the above summary, temperature and photoperiod appeared to be two major factors determining fruiting and production of annual-fruiting red raspberries. According to our former study (Wei et al., 2013), however, manipulation of photoperiod may cause inherent nutrient dilution within a growing plant even at a proper temperature. Over-decline of nutrient reserve could impair fruiting because both flowering and fruit production needed to utilize nutrients by translocation (Strik and Bryla, 2015). This contributes to the necessity to supply red raspberries with additional nutrients under the extended photoperiod to improve nutrient uptake and to warrant the potential of advanced fruiting.

Dalian City, Liaoning Province, Northeast China has an area of 330 ha for raspberry cultivation. Also, Dalian City has the crucial harbors for export red raspberry fruit productions to Korea, Japan, Russia, and the Americas. 'Autumn Bliss' (Great Britain, Plant Patent \#6597) is early ripening red raspberry cultivar with large and highly flavored fruits. It ripens 10 to 14 days before heritage. Much of the crop is produced within the first two weeks of harvest, which is an advantage in Northern climates. It produces short canes with few spines. It is susceptible to raspberry bushy dwarf virus (Weber, 2012). Generally, several studies have been conducted on 'Autumn Bliss' (Carew et al., 2003; Oliveira et al., 2004; Neocleous et al., 2005; Neocleous and Vasilakakis, 2007; Dragišić Maksimović et al., 2013) and some have confirmed that the prolonged photoperiod stimulated shoot growth of 'Autumn Bliss', but the specific effects could not be conclusive from $8 \mathrm{~h}$ to $17 \mathrm{~h}$ (Carew $e t$ al., 2003). In the present study, 'Autumn Bliss' was planted in a greenhouse in Dalian City with extended photoperiod and additional nutrient supply. It was hypothesized that: (i) fruiting of 'Autumn Bliss' cannot be advanced by long photoperiod unless additional nutrient supply was involved, and (ii) secondary metabolism in fruits would not change too much compared to in those under the ordinary condition.

\section{Materials and Methods}

\section{Plantmaterials}

The experiment was conducted in 2015 in a greenhouse at Pulandian Town of Dalian City (39 $19^{\circ}$ N, $121^{\circ} 49^{\prime}$ E), Liaoning Province, Northeast China. 'Autumn Bliss' was supplied as plantlets from micro-propagation by Prof. Zhang from Chinese Academy of Sciences. Briefly, canes with buds from mature 'Autumn Bliss' plants were collected and divided into segments, sterilized, and cultured on the induction medium. The first generations were continuously cultured on the multiplication medium and induced for root egress. Rooted plantlets were moved to pots filled with sands and peat (Zhilunpudao Agric. Tech. Ltd., Changchun, Jilin, China) in a greenhouse and cultured for $10 \mathrm{~d}$. During this time, indoor temperature and relative humidity were controlled to be $13 \sim 23{ }^{\circ} \mathrm{C}$ and $50 \sim 70 \%$, respectively. In April 2015, plantlet stocks were transplanted to planting beds of the greenhouse for this experiment for another shading-culture of $15 \mathrm{~d}$ until most plantlets grew to have new leaves.

\section{Experiment conduction and design}

The soils in the greenhouse corresponded to a clayloamy texture with a maximum depth of $3 \mathrm{~m}$. Soils at the top $30 \mathrm{~cm}$ were collected and analyzed to determine the $\mathrm{pH}$ of 5.2, organic matter content of $13 \%$, bulk density of 1.1 $\mathrm{Mg} \mathrm{m}^{-3}$, total $\mathrm{N}$ of $2.8 \mathrm{~g} \mathrm{~kg}^{-1}$, total $\mathrm{P}$ of $0.5 \mathrm{~g} \mathrm{~kg}^{-1}$, total $\mathrm{K}$ of 
442

$13 \mathrm{~g} \mathrm{~kg}^{-1}$. Before transplant, soils of planting beds were amended by local poultry manure. Chemical analysis indicated contents as total $\mathrm{N}$ of $25.6 \mathrm{~g} \mathrm{~kg}^{-1}$, organic matter of $499 \mathrm{~g} \mathrm{~kg}^{-1}, \mathrm{NH}_{4}^{+}-\mathrm{N}$ of $4.6 \mathrm{mg} \mathrm{kg}$, organic carbon (C) of $184.3 \mathrm{~g} \mathrm{~kg}^{-1}$, and $\mathrm{C} / \mathrm{N}$ ratio of 7.67 . Three planting beds were employed in this study and each had the length of $7 \mathrm{~m}$ and width of $0.5 \mathrm{~m}$. Each planting bed received one photoperiod regime and two adjacent beds were separated by black-out curtains to eliminate lateral light impact.

The experiment was conducted as a random plot design with three treatments placed at three planting beds. In one bed, plantlets were cultured with additional fertilizers under extended photoperiod for $17 \mathrm{~h}$ by supplementing illumination from 18:00 to 1:00 the next day (labeled as Pho.+Fert.); in the second bed, plantlets were cultured with the same photoperiod regime without any additional fertilizer supply (labeled as Pho.); in the last bed, neither supplementary lighting nor additional fertilizer was applied (labeled as the control). Each planting bed was divided into seven plots with the area of $0.5 \mathrm{~m} \times 1 \mathrm{~m}$ for each plot. Every two adjacent plots were separated by plastic cloth inserted into soils at the depth of $50 \mathrm{~cm}$ to eliminate lateral impact of fertilizers. Two plots at the two ends of the planting bed were left out of the experiment design as the buffer plot to eliminate possible edge effect by exogenous environment of the planting beds. The left five plots in each planting bed were involved as randomly placed replicates as treatment units.

\section{Plantlet culture}

Daytime light was only from the natural source unless the photosynthetic photon flux density (PPFD) declined to lower than $200 \mu \mathrm{mol} \mathrm{m}{ }^{-2} \mathrm{~s}^{-1}$ in cloudy or rainy days when lamps were open. Supplementary light at dark-time was supplied at the PPFD intensity of $240 \mu \mathrm{mol} \mathrm{m} \mathrm{m}^{-1}$ at the apical floral bud level. This light intensity has been proven to promote flowering in 'Autumn Bliss' (Carew et al., 2003). Artificial lighting was supplied by $200-\mathrm{W}$ plant growth lamps (Zhilunpudao ${ }^{\circ}$ Agric. Tech. Ltd., Changchun, Jilin, China). The light spectrum of these lamps has been tested to be effective for plant growth for several times (e.g. Wei et al., 2013; Zhu et al., 2016). One week after transplant, nutrients were delivered through Osmocote controlled release fertilizer (Scotts UK Ltd., Nottinghamshire, UK) at the rate of $12 \mathrm{~g}$ per plant $(\mathrm{N}$ -
$\mathrm{P}_{2} \mathrm{O}_{5}-\mathrm{K}_{2} \mathrm{O}$, 14-14-14, micronutrients plus). This fertilizer regime has also been employed for the culture of 'Autumn Bliss' by Carew et al. (2001) and Sønsteby and Heide (2009). Nutrients were broadcasted along two lateral furrows of each planting bed to the depth of $10 \mathrm{~cm}$ and then covered by soils.

Plantlets were transplanted to the density of 49 canes bed $^{-1}$ translating to 14 canes $\mathrm{m}^{-2}$ and 7 canes $\mathrm{m}^{-1}$ (with the width of $0.5 \mathrm{~m}$ ). This density was practical for the culture of red raspberry locally in Dalian City. Also the density of 14 canes $\mathrm{m}^{-2}$ was quite close to that generating maximum fruit yield following the treatment of pruning (Oliveira $e t$ al., 2004). Canes were pruned for floral buds in crowns during vegetative growth period at mid-May, early June, and midJune, 2015. About ten days after the final pruning flowers were initiated in the Pho.+Fert. treatment. Subsequently, at early July, 2015 fruits started to come out in this treatment until the late July when all fruits grew mature (Fig. 1). No plants in the Pho. treatment and the control had any fruits until late July, 2015; hence, the experiment was terminated at this time. Throughout the experiment, temperature for day/night was measured to be $25.8 / 17.1{ }^{\circ} \mathrm{C}$, respectively. Highest/lowest relative humidity was 84.3/36 \%, respectively. Weeds were controlled manually every week. Temperature inside the greenhouse was controlled with the ambient one by rolling the greenhouse-cover up and down at day and night, respectively.

\section{Plantlets sampling and chemical analysis}

Three plantlets were randomly sampled from each treatment plot and bulked as a replicate unit. Parameters were determined for each of these three samplings but their results were averaged as a mean for the replicate. When sampling, roots were carefully shovelled out to keep the root system out of harm. Sampled plantlets were firstly measured for morphological parameters of shoot (cane) length, diameter $3 \mathrm{~cm}$ above ground, root length at the steady status, and root volume by measuring the replaced water in a given volume. After morphological measurement, plantlets were divided into parts of leaves, stem, and root and ovendried at $70{ }^{\circ} \mathrm{C}$ for a week. Dried samples were measured for biomass and determined for total concentrations of N, P, and K. Soils were also sampled at the top $30 \mathrm{~cm}$ from the plots where plantlets were shovelled. Sampled soils were smashed, air-dried for half a month, and prepared for
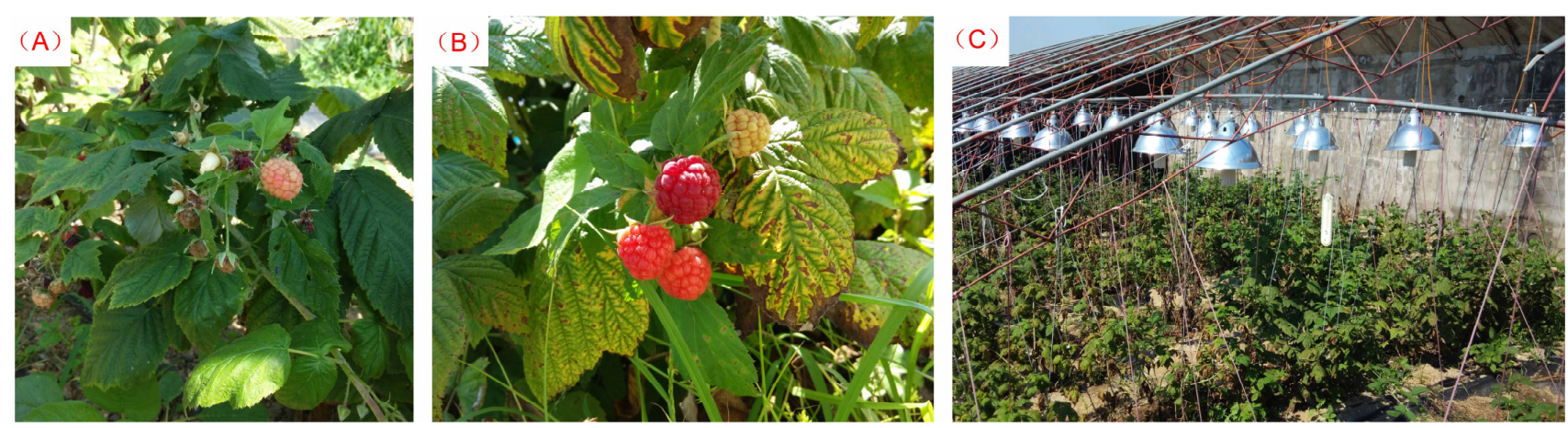

Fig. 1. Fruits of red raspberry (Rubus idaeus L.) 'Autumn Bliss' plantlets at early July, 2015 (A) and mature fruit at end of July, 2015 (B) after treated by additional fertilizer addition under extended photoperiod. (C) At harvest time, both cover over the greenhouse and black-out curtains between planting beds were removed to facilitate plantlet and fruit sampling 
chemical analysis of available N, P, and K. Because fruits were only produced in the Pho.+Fert. treatment they did not take part in the comparison among treatments but harvested for three times at early, mid-, and end of July, 2015. Fruits were measured for length, diameter, weight, and number of setting fruits (fallen ones were not counted because they corrupted very soon and quite few have fallen). Harvested fruits were ice-stored until the laboratory and analyzed for contents of antioxidants therein, included anthocyanin, gallic acid, and total phenolics.

Total N, P, and $\mathrm{K}$ were determined according to the methodology described by Wei et al. $(2013,2014)$ and Wang et al. (2016). Soil available N, P, and K were determined by the method of Guo et al. (2016) and Zhu et al. (2016). Fruit antioxidants were analyzed according to the methods by Bobinaite et al. (2012) and Dragišić Maksimović et al. (2013).

\section{Statistical analysis}

Nutrient utilization index (NUI) was involved to estimate nutrient utilized by red raspberry which was calculated as (Hawkins, 2007):

\section{$N U I=$ Massleaf $_{\text {leaf }}$}

where, Massleaf and $\mathrm{N}_{\text {leaf }}$ were the biomass $(\mathrm{g})$ and nutrient $(\mathrm{N}, \mathrm{P}$, and $\mathrm{K})$ concentration $\left(\mathrm{mg} \mathrm{g}^{-1}\right)$, respectively. Vector analysis was also employed to evaluate the status of nutrient content and concentration according to the method described by Wei et al. (2013) and Wang et al. (2016). Regression analysis was performed between soil nutrients and plantlet parameters about root growth and foliar nutrient concentration. ANOVA analysis was conducted on all parameters when significant effect was indicated results were compared and arranged according to LSD test at the 0.05 level. All data were analyzed by SAS 9.2 (SAS Institute, Cary, NC, USA). Temperature and humidity data in this study were all obtained by the web of Weather Underground (https://www.wunderground.com/).

\section{Results}

\section{Plantlet growth}

The Pho.+Fert. treatment resulted in greater shoot length, shoot diameter, and root length than the Pho. treatment and the control (Table 1). Compared to the control, shoot height, shoot diameter, and root length increased by $40 \%, 45 \%$, and $79 \%$, respectively in the Pho.+Fert. treatment. While compared to the Pho. treatment, these parameters increased by $34 \%, 31 \%$, and $76 \%$, respectively. The Pho.+Fert. treatment also increased root volume by $98 \%$ relative to the control, but results between Pho.+Fert. treatment and Pho. treatment was not statistically different (Table 1).

\section{Plantlet biomass}

The Pho.+Fert. treatment resulted in the increase of foliar biomass by $112 \%$ and $85 \%$ relative to the Pho. treatment and the control, respectively $(P=0.0056)$ (Fig. 2$)$. However, the Phol+Fert. treatment did not increased stem biomass relative to the Pho. treatment although it increase stem biomass relative to the control by $94 \%(P=0.0265)$. Root biomass did not respond to any treatment $(P=0.8426)$. Root to shoot biomass ratio did not respond to any treatments $(P=0.2750)$ which ranged from 0.5 to 0.8 .

\section{Plantlet nutrient concentration and utilization}

Both treatments of Pho.+Fert. and Pho. resulted in the decline of foliar nutrients for $\mathrm{N}, \mathrm{P}$, and $\mathrm{K}$ (all three, $P<0.0001$ ) (Fig. 3). Relative to the control, average declines for $\mathrm{N}, \mathrm{P}$, and $\mathrm{K}$ in treated plantlets ranged in $17 \sim 22 \%$, $20 \sim 28 \%$, and 30 36\%, respectively. Stem N and K concentrations were higher in the Pho.+Fert. treatment by $36 \%$ and $40 \%$, respectively compared to those in the control, while stem P concentration in the Pho.+Fert. treatment decreased by $19 \%$. In contrast to results about foliar $\mathrm{N}$ concentration, root $\mathrm{N}$ concentration was increased by $45 \%$ in the Pho.+Fert. treatment relative to the control.

Nutrient utilization index (NUI) was higher in the Pho.+Fert. treatment than the Pho. treatment and the control for $\mathrm{N} \quad(P=0.0058), \mathrm{P} \quad(P=0.0179)$, and $\mathrm{K}$

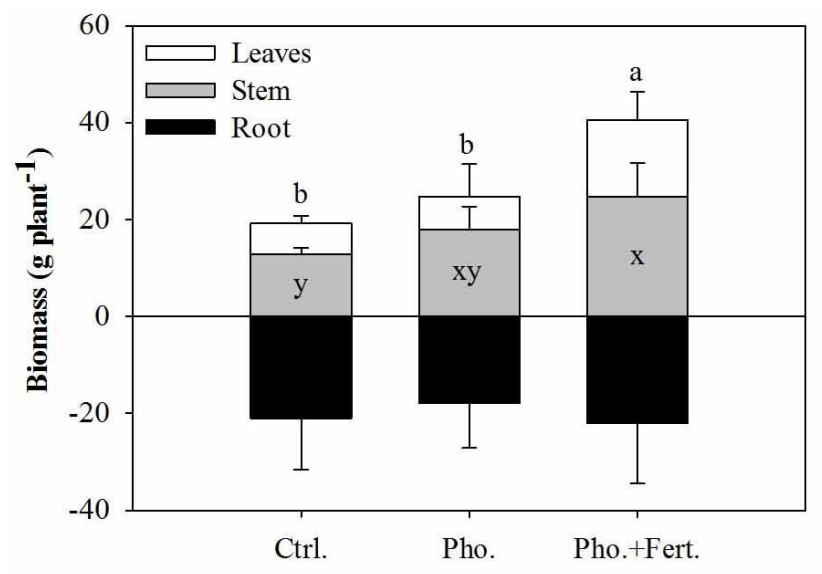

Fig. 2. Biomass in leaves, stem, and root of red raspberry (Rubus idaeus L.) 'Autumn Bliss' plantlets in response to the control, the Extended photoperiod (Pho.) treatment, and the additional fertilization plus extended photoperiod (Pho.+Fert.) treatment. Different letters indicate significant difference among treatments at the 0.05 level. For biomass results $\mathrm{a}$ and $\mathrm{b}$ indicate for leaves; $\mathrm{x}$ and $\mathrm{y}$ indicate for stem biomass

Table 1. Morphological parameters of raspberry plantlets in response to the control (Ctrl.), and treatments of supplementary photoperiod (Pho.) and Pho. plus fertilizer (Pho.+Fert.)

\begin{tabular}{|c|c|c|c|c|}
\hline Treatments & Shoot length $(\mathrm{cm})$ & Shoot diameter $(\mathrm{mm})$ & Root length $(\mathrm{cm})$ & Root volume $\left(\mathrm{cm}^{3}\right)$ \\
\hline Cetrl. & $107.56 \pm 12.76 b$ & $9.75 \pm 1.65 b$ & $18.80 \pm 2.20 \mathrm{~b}$ & $34.20 \pm 5.36 b$ \\
\hline Pho. & $112.58 \pm 18.81 \mathrm{~b}$ & $10.84 \pm 0.78 b$ & $19.20 \pm 6.63 b$ & $53.60 \pm 23.66 \mathrm{ab}$ \\
\hline Pho.+Fert. & $150.64 \pm 27.43 a$ & $14.17 \pm 2.08 \mathrm{a}$ & $33.70 \pm 10.19 a$ & $67.80 \pm 18.34 \mathrm{a}$ \\
\hline
\end{tabular}

Note: different letters in a column indicate significant difference at 0.05 level. 
444

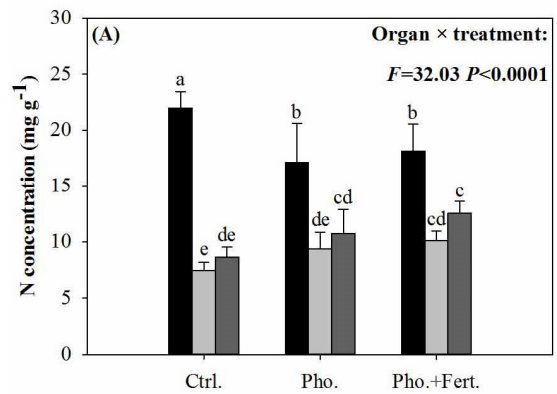

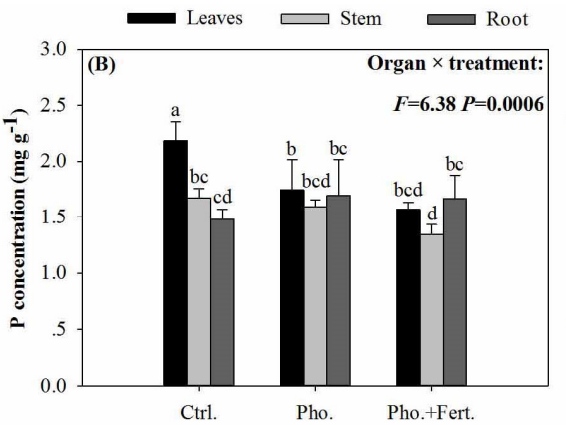

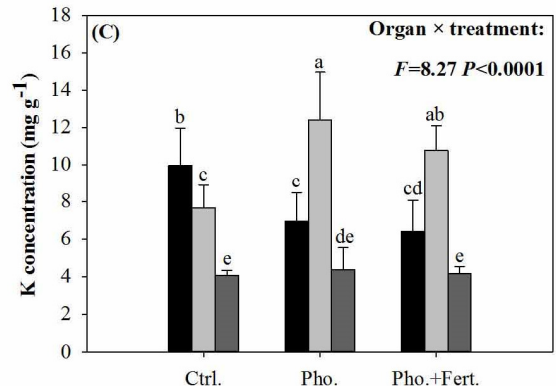

Fig. 3. Nutrient concentrations of N (A), P (B), and K (C) in leaves, stem, and root of red raspberry (Rubus idaeus L.) 'Autumn Bliss' plantlets treated with the control, the extended photoperiod (Pho.) treatment, and the additional fertilization plus extended photoperiod (Pho.+Fert.) treatment. Different letters indicate significant difference among treatments at the 0.05 level

Table 2. Nutrient utilization indices for $\mathrm{N}, \mathrm{P}$, and $\mathrm{K}$ in raspberry plantlets in response to the control (Ctrl.), and treatments of supplementary photoperiod (Pho.) and Pho. plus fertilizer (Pho.+Fert.)

\begin{tabular}{cccc}
\hline Treatments & $\mathrm{N}$ & $\mathrm{P}$ & $\mathrm{K}$ \\
\hline Ctrl. & $0.35 \pm 0.07 \mathrm{~b}$ & $3.62 \pm 1.06 \mathrm{~b}$ & $0.83 \pm 0.31 \mathrm{~b}$ \\
Pho. & $0.40 \pm 0.14 \mathrm{~b}$ & $3.83 \pm 1.19 \mathrm{~b}$ & $0.97 \pm 0.26 \mathrm{~b}$ \\
Pho.+Fert. & $0.85 \pm 0.48 \mathrm{a}$ & $9.26 \pm 4.50 \mathrm{a}$ & $2.45 \pm 1.94 \mathrm{a}$ \\
\hline
\end{tabular}

Note: different letters in a column indicate significant difference at 0.05 level.

$(P=0.0076)$ (Table 2). Relative to the control, the Pho.+Fert. and the Pho. treatments increased NUI for N, P, and $\mathrm{K}$ by $110 \sim 141 \%, 142 \sim 156 \%$, and $153 \sim 194 \%$, respectively.

\section{Soil nutrient availability}

Neither soil available $\mathrm{N}$ nor soil available $\mathrm{K}$ responded to any treatment $(P=0.9837$ and $P=0.3051$, respectively), which ranged around $0.31 \mathrm{mg} \mathrm{kg}^{-1}$ and $0.14 \mathrm{mg} \mathrm{kg}^{-1}$, respectively. However, soil available $\mathrm{P}$ concentration responded to treatments $(P=0.0026)$. Relative to the control, soil available $\mathrm{P}$ concentration declined by $31 \%$ and $19 \%$ in the Pho.+Fert. and the Pho. treatments, respectively (Fig. 4).

Pearson correlation indicated no relationship between soil and foliar nutrient concentrations except for $P$ element $(R=0.7159, P=0.0027)$. The relationship between soil available $\mathrm{P}$ concentration and foliar $\mathrm{P}$ concentration can also be described by a spearman correlation $(R=0.7250$, $P=0.0022)$. Likewise, spearman correlation was also retained in the relationship between soil $\mathrm{P}$ concentration

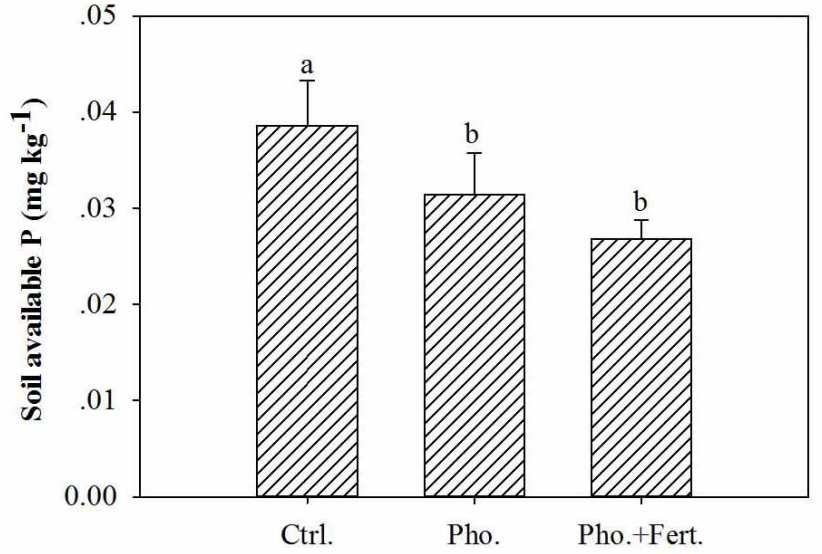

Fig. 4. Soil P content for the culture of red raspberry (Rubus idaeus L.) 'Autumn Bliss' plantlets in response to the control, the Extended photoperiod (Pho.) treatment, and the additional fertilization plus extended photoperiod (Pho.+Fert.) treatment. Different letters indicate significant difference among treatments at the 0.05 level

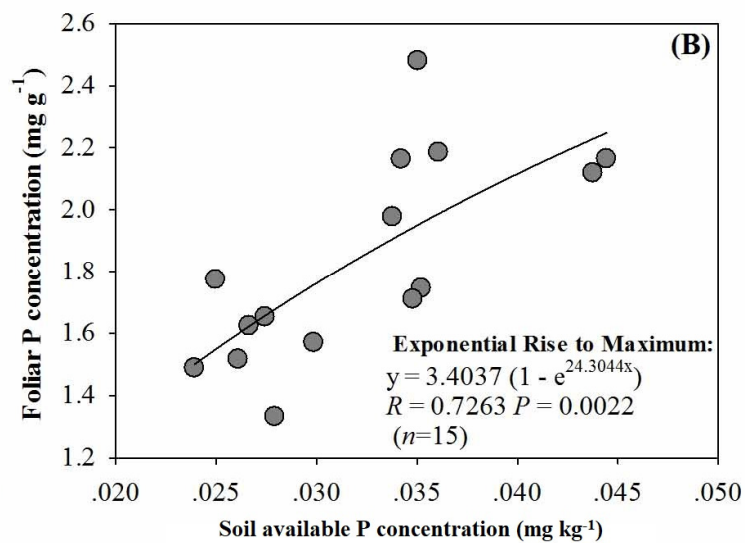

Fig. 5. Non-linear regression analysis of soil available P concentration on root length (A) and foliar P concentration (B) red raspberry (Rubus idaeus L.) 'Autumn Bliss' plantlets 
and root length $(R=-0.6041, P=0.0171)$. Regression analysis indicated a non-linear negative relationship of polynomial between soil $\mathrm{P}$ concentration and root length (Fig. 5a) and a non-linear positive relationship of exponential-rise between soil $\mathrm{P}$ concentration and foliar $\mathrm{P}$ concentration (Fig. 5b).

\section{Vector analysis}

When compositing nutrient content, nutrient concentration and biomass in leaves for vector analysis, 'Autumn Bliss' plantlets in the Pho.+Fert. treatment showed apparent symptom of nutrient dilution for all three elements relative to the control due to stimulated biomass with the decline of nutrient concentration (Fig. 6). Otherwise, the Pho. treatment induced the foliar symptom of nutrient depletion for all three elements due to unchanged biomass but decreased nutrient concentration.

\section{Fruit traits}

Fruit length and diameter increased since the developed fruiting stage but difference was not significant between the developed and end fruiting stages (length, $P=0.0018$; diameter, $P=0.0001$ ) (Table 3). The ratio of fruit length to diameter ratio did not change with time which ranged between $1.1 \pm 0.03$ and $1.14 \pm 0.05$. In contrast, setting fruit number declined with time $(P=0.0003)$. Single fruit weight increased from the initial fruiting stage to the developed one by $19 \%$ then declined by $11 \%(P<0.0001)$. Similar trends emerged also for all parameters of antioxidants. Apparently, gallic acid content $(P=0.0003)$ was higher than anthocyanin $(P<0.0001)$ and total phenolic content $(P<0.0001)$.

\section{Discussion}

Generally in Northeast China, annual-fruiting cultivars, such as 'Autumn Bliss', initiate flowering in July and start to fruit since September to October following the common treatment of floral bud pruning. However, 'Autumn Bliss' plantlets in our study advanced their flowering and fruiting phenology by about two months in the combined treatments of extended photoperiod and additional fertilizer application. Therefore, it is reasonable to accept our first hypothesis. In Dalian City, the maximum and
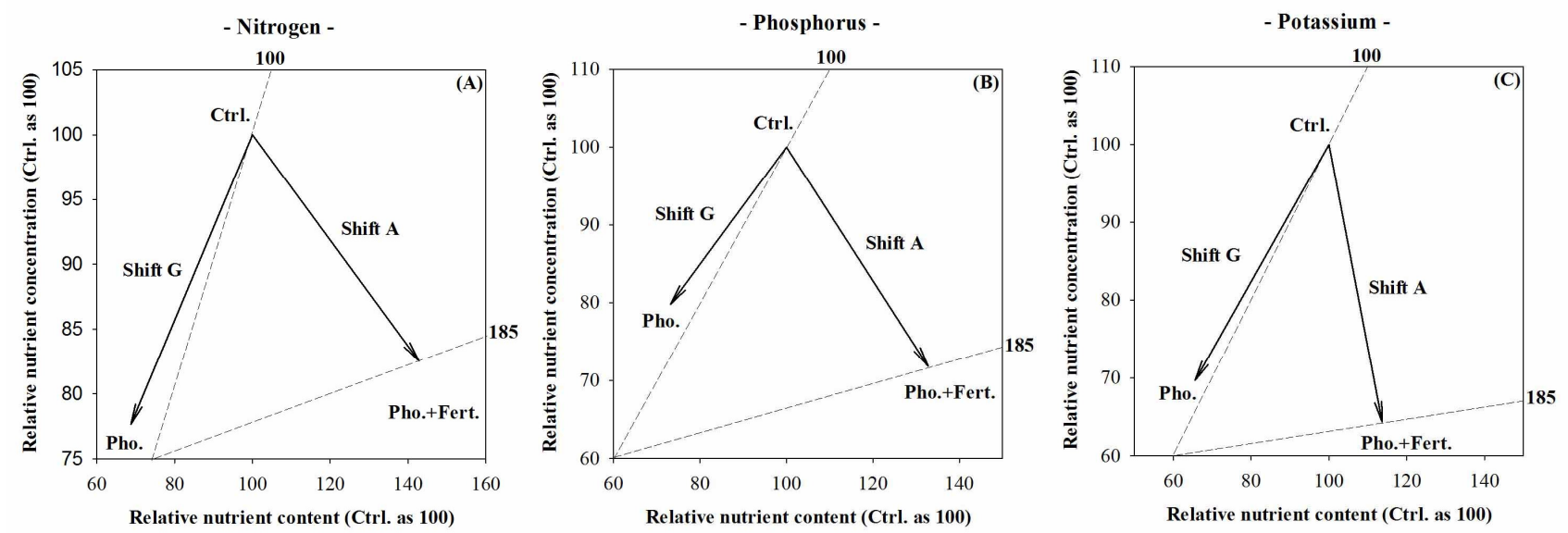

Fig. 6. Vector nomogram of relative change in nutrient content, nutrient concentration and biomass in leaves of red raspberry (Rubus idaeus L.) 'Autumn Bliss' plantlets in response to the control, the extended photoperiod (Pho.) treatment, and the additional fertilization plus extended photoperiod (Pho.+Fert.) treatment. The type of nutritional response induced by enrichment is characterized by shift (or vector) direction and magnitude. Shift A indicates the symptom of nutrient dilution possibly caused by growth stimulation without sufficient nutrient supply; shift $G$ indicates the symptom of nutrient decline possibly caused by nutrient depletion

Table 3. Fruit parameters of raspberry plantlets treated with supplementary photoperiod plus fertilizer application at three fruiting stages

\begin{tabular}{|c|c|c|c|}
\hline \multirow{2}{*}{ Fruit parameters } & \multicolumn{3}{|c|}{ Fruiting stage } \\
\hline & Initial & Developed & End \\
\hline \multicolumn{4}{|c|}{ Growing trait } \\
\hline Length $(\mathrm{cm})$ & $1.71 \pm 0.05 \mathrm{~b}$ & $1.81 \pm 0.03 \mathrm{a}$ & $1.85 \pm 0.05 \mathrm{a}$ \\
\hline Diameter $(\mathrm{cm})$ & $1.50 \pm 0.05 b$ & $1.62 \pm 0.04 \mathrm{a}$ & $1.67 \pm 0.03 \mathrm{a}$ \\
\hline Setting fruit number & $24 \pm 1.77 \mathrm{a}$ & $20 \pm 1.46 b$ & $18 \pm 1.46 b$ \\
\hline Fruit weight (g) & $2.77 \pm 0.08 \mathrm{c}$ & $3.30 \pm 0.07 \mathrm{a}$ & $2.92 \pm 0.12 b$ \\
\hline \multicolumn{4}{|c|}{ Antioxidants } \\
\hline Anthocyanin (mg cyaniding-3-glucoside equiv. $100 \mathrm{~g}^{-1} \mathrm{Fw}$ ) & $25.40 \pm 1.44 \mathrm{~b}$ & $38.66 \pm 5.88 \mathrm{a}$ & $15.12 \pm 1.01 \mathrm{c}$ \\
\hline Ellagic acid $\left(\mathrm{mg} 100 \mathrm{~g} \mathrm{~g}^{-1} \mathrm{Fw}\right)$ & $80.42 \pm 7.62 b$ & $97.60 \pm 10.04 a$ & $60.68 \pm 9.64 c$ \\
\hline Total phenolic content (mg GAE $\left.100 \mathrm{~g}^{-1} \mathrm{Fw}\right)$ & $18.18 \pm 1.59 b$ & $22.53 \pm 2.60 \mathrm{a}$ & $11.90 \pm 0.90 \mathrm{c}$ \\
\hline
\end{tabular}

Different letters in a horizon row indicate significant difference at 0.05 level. 

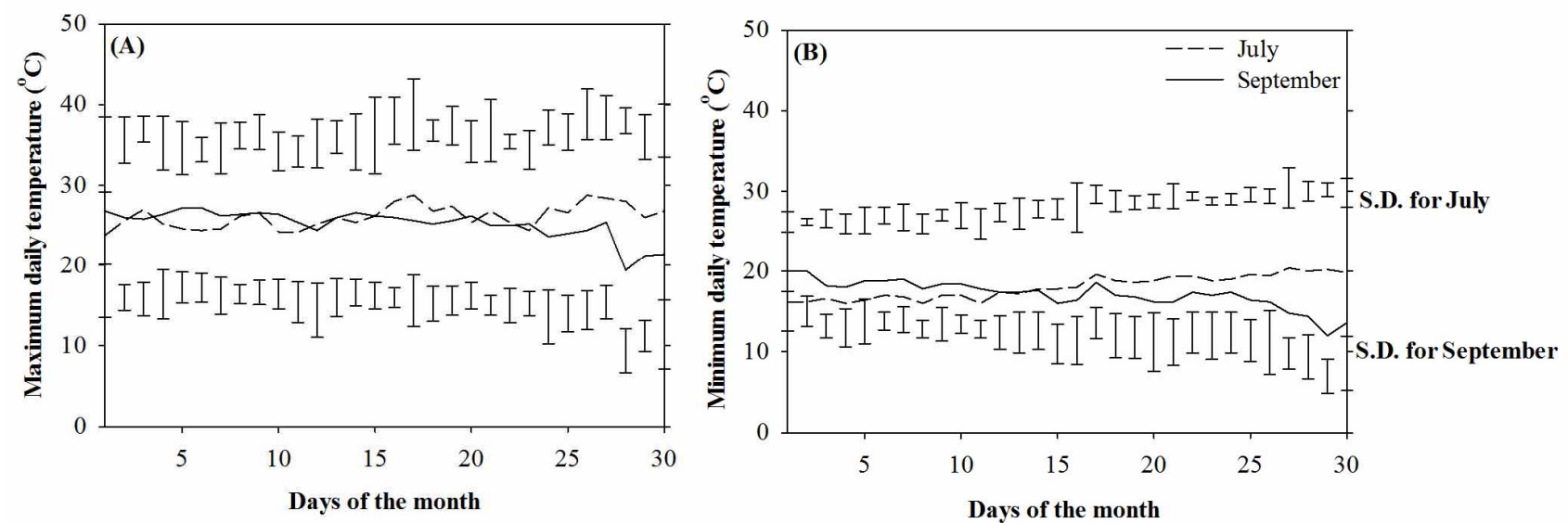

Fig. 7. Dynamics for maximum (A) and minimum temperatures (B) in July and September at Dalian City with data from the most recent five years $(2012 \sim 2016)$

minimum temperatures in July were $26.13 \pm 2.27^{\circ} \mathrm{C}$ and $18.4 \pm 1.47^{\circ} \mathrm{C}$, respectively, and they were $25.22 \pm 2.13^{\circ} \mathrm{C}$ and $17.13 \pm 2.17{ }^{\circ} \mathrm{C}$, respectively in September (Fig. 7). Hence both maximum and minimum temperature in July was higher than those in September (Max, $P=0.0058$; Min, $P=0.0011)$. However, the increment of temperature between the two months was only $\pm 1{ }^{\circ} \mathrm{C}$. The general temperature in both months fell in the most proper temperature range for the culture of annual-fruiting red raspberry (Carew et al., 2003; Sønsteby and Heide, 2012). Temperature during fruiting the greenhouse of our study was higher than ambient one by about $5 \sim 6^{\circ} \mathrm{C}$, which touched the highest temperature of floral primordial initiation of $30^{\circ} \mathrm{C}$ (Sønsteby and Heide, 2009). Therefore, summer temperature in Dalian City is suitable for the culture of annual-fruiting red raspberry, which does not need further examination.

Our results showed that the single effect of extended photoperiod was unable to change any parameters of plantlet growth and biomass unless combined with additional fertilization to 'Autumn Bliss'. These results disagreed with findings by Sønsteby and Heide (2009; 2012) where the main effect of photoperiod was quite significant on shoot elongation of annual-fruiting cultivars. This might be related to the interaction with temperature, which was much lower in Norway $\left(\sim 60^{\circ} \mathrm{N}\right)$ and varied in the experiments therein. When temperature was not limited, main effect of photoperiod on red raspberry growth may be impaired as a response. However, when additional fertilization was involved growth was promoted. This suggested that fertilizer addition had significant effect on growth of red raspberry under a given photoperiod. Similar results were also obtained by Lockshin and Elfving (1981) and DeGomez et al. (1986).

Although root biomass in our study did not respond to treatments, root length showed significantly decline trend with the increase of soil $\mathrm{P}$ availability while foliar $\mathrm{P}$ concentration increased accordingly. These results together suggested that 'Autumn Bliss' is sensitive to soil P availability by the response of root proliferation and $\mathrm{P}$ uptake to leaves. Actually, different plant species showed divergent morphological response to $P$ availability and some crops allocated more sources to support root elongation hence enhance P uptake and some others showed reverse response (Wang et al., 2015). According to our study, 'Autumn Bliss' chose the strategy to facilitate shoot P concentration at the cost of root morphology when $\mathrm{P}$ availability was enhanced by fertilization.

It is interesting that under the extended photoperiod foliar biomass was stimulated but nutrients declined which was evaluated to be the symptom of nutrient dilution. Similar results have also been mentioned and reported on tree seedlings (Wei et al., 2013). Foliar dilution of nutrients in our study was unlikely caused by nutrient leaching impact because according to Zhu et al. (2016) where photoperiod appeared to have very weak influence on leachate events. Unlike tree crops whose termination was ended with vegetative growth, red raspberries' termination is with fruiting. Hence, foliar nutrient dilution in our study should be partly caused by the high utilization of nutrient for biomass accumulation and more tendentiously used for fruiting. This was reasonable because fruiting was advanced by the extended photoperiod and additional fertilization after all. On the other hand, in the Pho. treatment where no additional fertilizer was applied foliar biomass did not change from that in the control while foliar nutrients declined (Figs. 2 and 5). These results together suggested that photoperiod stimulated biomass consumption without any contribution to growth or biomass accumulation under the condition without sufficient nutrient supply in 'Autumn Bliss'.

Fruits were only produced in the Pho.+Fert. treatment, hence they were compared with those from other studies. Although fruit weight in our study was comparable to that in Dai and Liao (2011) (3g plant $\left.{ }^{-1}\right)$, the total yield per plantlet for 'Autumn Bliss' in our study $\left(\sim 55 \mathrm{~g}\right.$ plant $\left.^{-1}\right)$ was only one tenth of that in the cultivar 'Heritage' in Beijing $\left(\sim 550 \mathrm{~g} \mathrm{plant}^{-1}\right)$ (Xu et al., 2015). Recent studies revealed that fruit yield in annual-fruiting cultivars in Norway was even much greater at the level of $1 \sim 3 \mathrm{~kg}$ per plant (Sønsteby et al., 2013). Therefore, although fruiting of 'Autumn Bliss' was successfully advanced by combined photoperiod and fertilization treatments, the fruiting yield was still limited by number of setting fruits.

Phenolics are important bioactive compounds and antioxidant, which can be divided into simple phenols, 
phenolic acids, phenylpropanoids and flavonoids (Takahama and Oniki, 2000). The anthocyanins are natural pigments belonging to the flavonoid family. In berries, a multiple of phenolic compounds have been detected, including flavanols and phenolic acids (Pantelidis et al., 2007). Ellagnic acid released after hydrolysis was the main phenolic compound in the berries belonging to the genus Rubus, constituting $77-88 \%$ of the total phenolic acids (Häkkinen et al., 1999). In our study, anthocyanin content in fruit extracts during developed fruiting stage (Mid-July) of 'Autumn Bliss' in our study (Table 3 ) concurs with that in the same cultivar of Pantelidis et al. (2007), and our anthocyanin results at the end of fruiting stage (late July) was comparable with those in Dragišić Maksimović et al. (2013). Ellagic acid content in our study was generally about two thirds of that in Bobinaite et al. (2012). In addition, our total phenolic content was comparable with that in fruit of 'Autumn Bliss' in Pantelidis et al. (2007) ( 10-20 mg GAE $\left.100 \mathrm{~g}^{-1} \mathrm{Fw}\right)$ but much lower than that in Bobinaite et al. (2012) and Dragišić Maksimović et al. (2013). Hence, it seemed that combined treatments of extended photoperiod and additional fertilization in our study increased flavonoids components by the promotion of anthocyanin contents but showed little effect on phenolic acids according to ellagnic acid content. Unlike the traditional vitamins, anthocyanins are not essential for short-term well-being but can modulate human metabolism in a manner of long-term manner of intakes to prevent the health risk. These together suggested that total phenolic contents in fruits of 'Autumn Bliss' of our study can be acceptable for the usage of antioxidation due to the fair content of anthocyanin.

\section{Conclusions}

Our results showed that fruiting of red raspberry cultivar 'Autumn Bliss' can be advanced from September to July in temperate region at the latitude of about $40^{\circ}$, such as Dalian City, Liaoning Province, Northeast China. Temperature throughout the experiment was measured to range about $15-26^{\circ} \mathrm{C}$, which has been determined to be the proper for growth and reproduction of red raspberry by former studies. Manipulations contributing to advanced fruiting mainly included the additional fertilization at the rate of $12 \mathrm{~g}$ per plant ( $\mathrm{N}-\mathrm{P}_{2} \mathrm{O}_{5}-\mathrm{K}_{2} \mathrm{O}$, 14-14-14, micronutrients plus) under extended photoperiod of $17 \mathrm{~h}$ with PPFD of $240 \mu \mathrm{mol} \mathrm{m}^{-2} \mathrm{~s}^{-}$ ${ }^{1}$ at dark-time. Both growth and biomass in shoot part of 'Autumn Bliss' were promoted by these treatments, but foliar nutrients declined as the symptom of nutrient dilution. Single treatment of extended photoperiod without additional fertilization affected neither growth nor nutrient uptake in leaves, resulting in the symptom of nutrient depletion. Both weight and anthocyanin content for fruit can be acceptable but fruit number per plant was much fewer, resulting yield to be quite lower compared to that from ordinary culture. In conclusion, combined treatments of extended photoperiod and additional fertilization can advance fruiting time of 'Autumn Bliss' and anthocyanin acted as the main antioxidant therein, but yield was limited by fruit number which needs more studies to improve in future.

\section{Acknowledgements}

This work was financially supported by the National Natural Science Foundation of China (31771695; 31600496; 31301814) and National Torch Plant Project (2012GH531899), National Key Technologies R\&D Program of China (2016YFC0500300), and Liao ning province Natural Science Foundation (20170540208).

\section{References}

Bobinaitè R, Viškelis P, Venskutonis PR (2012). Variation of total phenolics, anthocyanins, ellagic acid and radical scavenging capacity in various raspberry (Rubus spp.) cultivars. Food Chemistry 132:1495-1501.

Carew JG, Mahmood K, Darby J, Hadley P, Battey NH (2001). The effects of low temperatures on the vegetative growth and flowering of the primocane fruiting raspberry 'Autumn Bliss'. Journal of Horticultural Sciences and Biotechnology 76:264-270.

CarewJG, Mahmood K, DarbyJ,Hadley P, BtteyNH (2003). The effect of temperature, photosynthetic photon flux density, and photoperiod on the vegetative growth and flowering of 'Autumn Bliss' strawberry. Journal of American Society of Horticultural Science 128:291-296.

Campos-Mota L, Baca-Castillo GA, Jaén-Contreras D, Muratalla-Lúay A, Acosta-Hernández R (2004). Fertirrigation and mycorrhiza in red raspberry cultured on tepetate. Agrociencia 38:75-83.

Dai HP, Liao SW (2011). The cultivation trial of three annual-fruiting red raspberries in Shenyang, Liaoning, China. China Fruits 3:40-43 (in Chinese).

Dean DM, Zebarth BJ, Kowlalenko CG, Paul JW, Chipperfield K (2000). Poultry manure effects on soil nitrogen processes and nitrogen accumulation in red raspberry. Canadian Journal of Plant Science 80:849-860.

DeGomez TE, Martin LW, Breen PJ (1986). Effect of nitrogen and pruning on primocane fruiting red raspberry 'Amity'. HortScience 21:441-442.

Dragišić Maksimović JJ Milivojević MM, Nikolić MD, Maksimović VM (2013). Profiling antioxidant activity of two primocane fruiting red raspberry cultivars (Autumn bliss and Polka). Journal of Food Composition and Analysis 31:173-179.

Guo P, Jin H, Wei HX, Li LL, Bao YJ (2016). Fine root growth and water use efficiency in alfalfa (Medicago sativa L. cv. Gongong No. 1) planted along a salinity gradient in coastal area of Dalian, Northeast China. Soil Science and Plant Nutrition 62:164172.

Häkkinen S, Heinonen M, Kärenlampi S, Mykkänen H, Ruuskanen J, Törrönen R (1999). Screening of selected flavonoids and phenolic acids in 19berries. Food Research International 32:345-353.

Hawkins BJ (2007). Family variation in nutritional and growth traits in Douglas-fir seedlings. Tree Physiology 27:911-919.

Heide OM, Sønsteby A (2011). Physiology of flowering and dormancy regulation in annual- and biennial-fruiting red raspberry (Rubus idaeus L.) - a review. Journal of Horticultural Science and Biotechnology 86:433-442.

Horuz A, Korkmaz A, Karaman MR, Dizman M, Turan M (2013). The evaluation of leaf nutrient contents and element ratios of different 
448 raspberry varieties. Journal of Food and Agricultural Environment 11:588-593.

Jones AT, McGavin WJ (1998). Infectibility and sensitivity of UK raspberry, blackberry and hybrid berry cultivars to Rubus viruses. Annals of Applied Biology 132:239-251.

Kowalenko CG (2006). The effect of nitrogen and boron fertilizer applications on Willamette red raspberry growth, and on applied and other nutrients in the plant and soil over two growing seasons. Canadian Journal of PlantScience 86:213-215.

Lockshin LS, Elfving DC (1981). Flowering response of 'Heritage' red raspberry to temperature and nitrogen. HortScience 16:527-528.

Neocleous D, Papadopoulos I, Vasilakakis M (2005). Investigating the possibility of fruiting primocane raspberries for off-season production in Cyprus. European Journal of Horticultural Science 70:89-95.

Neodeous D, Vasilakakis M (2007). Effects of $\mathrm{NaCl}$ stress on red raspberry (Rubusidaeus L. 'Autumn Bliss'). Scientia Horticulture 112:282-289.

Oliveira PB, Oliveira CM, Monteiro AA (2004) Pruning date and cane density affect primocane development and yield of 'Autumn Bliss' red raspberry. HortScience 39:520-524.

Pantelidis GE, Vasilakakis M, Manganaris GA, Diamantidis G (2007). Antioxidant capacity, phenol, anthocyanin and ascorbic acid contents in raspberries, blackberries, red currants, gooseberries and Cornelian cherries. Food Chemistry 102:777-783.

Sønsteby A, Heide OM (2008). Environmental control of growth and flowering of Rubus idaeus L. cv. Glen Ample. Scientia Horticulture 117:249-256.

Sønsteby A, Heide OM (2009). Effects of photoperiod and temperature on growth and flowering of the annual (primocane) fruiting raspberry (Rubus idaeus L.) cultivar 'Polka'. Journal of Horticultural Science and Biotechnology 84:439 446.

Sønsteby A, Heide OM (2012). Effects of photoperiod and temperature on growth, flowering and fruit yield in annual-fruiting red raspberry cultivars (Rubus idaeus L.). Journal of Horticultural Science and Biotechnology 77:97-108.

Sønsteby A, Stavang JA, Heide OM (2013). Production of high-yielding raspberry long canes: The way to $3 \mathrm{~kg}$ of fruit per cane. Journal of Horticultural Science and Biotechnology 88:591-599.

Strik BC, Bryla DR (2015). Uptake and partitioning of nutrients in blackberry and raspberry and evaluating plant nutrient status for accurate assessment of fertilizer requirements. Hort Technology 25:452459.

Takahama U, Oniki T (2000). Flavonoids and some other phenolics as substrates of peroxidase: physiological significance of the redox reactions. Journal of Plant Research 113:301-309.

USDA (2015). Noncitrus fruits and nuts: 2014 Preliminary summary. National Agricultural Statistics Service web. Retrieved 2015 February 15 fromhttp://www.nass.usda.gov/Publications/Todays_Reports/Report s/ncit0115.pdf.

Wang YL, Almvik M, Clarke N, Eich-Greatorex S, Oggaard AF, Krogstad T, Lambers H, Clarke JL (2015). Contrasting responses of root morphology and root-exuded organic acids to low phosphorus availability in three important food crops with divergent root traits. AoB Plants 7:plv097.

Weber C (2012). Raspberry variety review. Berry Resources, Cornell Fruit, Cornell cooperative extension, College of Agriculture and Life Sciences, Cornell University. Retrieved 2012 June 3 from http://www.fruit.cornell.edu/berry/.

Wei HX, Ren J, Zhou JH (2013). Effect of exponential fertilization on growth and nutritional status in Buddhist pine (Podocarpus macrophyllus [Thunb.] D. Don) seedlings cultured in natural and prolonged photoperiods. Soil Science and Plant Nutrition 59:933-941.

Wei HX, Xu CY, Ma LY, Duan J, Jiang LN, Ren J (2014). Effect of lateseason fertilization on nutrient reserves and carbohydrate accumulation in bareroot Larix olgensis seedlings. Journal of Plant Nutrition 37:279293.

Wang Z, Ma LY, Jia ZK, Wei HX, Duan J (2016). Interactive effects of irrigation and exponential fertilization on nutritional characteristics in Populus $\times$ euramericana cv. $74 / 76$ cuttings in an open-air nursery in Beijing, China.Journal of Forestry Research 27:569-582.

Xu YC,ZhangLL, ZhangQH, Wang YH,LiL, DongFX(2015).Effect of pinching and pruning on retarding cultivation of primocane-fruiting red raspberry. Journal of Northeast Agricultural University 46:50-55 (in Chinese with English abstract).

Yin XG, Olesen JE, Wang M, Öztürk I, Zhang HL, Chen F (2016). Impacts and adaptation of the cropping systems to climate change in the Northeast Farming region of China. European Journal of Agronomy 78:60-72.

Zhu KY,Liu HC, WeiHX,ZhouJH,Zou QC,MaGY,ZhangJQ(2016) Prediction of nutrient leaching from culture of containerized Buddhist pine and Japanese maple seedlings exposed to extended photoperiod. International Journal of Agriculture and Biology 18:425-434. 